\title{
Desempenho de híbridos de milho para consumo in natura em diferentes doses de nitrogênio
}

\section{Performance of corn hybrids grown under different levels of nitrogen and for in natura consumption}

\author{
Felipe Rodrigues COSTA ${ }^{1}$; Leandro Ferreira DAMASO ${ }^{1}$; Rafael Correia MENDES ${ }^{1}$; \\ Daiane Duarte MARQUES ${ }^{2}$; Fabrício RODRIGUES ${ }^{3}$

\begin{abstract}
${ }^{1}$ Engenheiros Agrônomos; Universidade Estadual de Goiás - UEG; felipe.rcosta@hotmail.com; leandrodamaso@yahoo.com.br; rafaelcorrea00@hotmail.com

2 Mestranda; Universidade Estadual de Goiás - UEG - Produção Vegetal; daiane.marques.floresta@gmail.com Departamento de Melhoramento Vegetal; Rodovia GO 330, km 241, Anel Viário, Ipameri, GO, CEP: 75780-000; fabricio.rodrigues@ueg.br
\end{abstract} \\ ${ }^{3}$ Autor para correspondência; Pós-doutor em Melhoramento Vegetal; Universidade Estadual de Goiás - UEG;
}

Recebido em: 02-06-2014; Aceito em: 05-12-2014

\section{Resumo}

O Brasil é um grande produtor de milho, entretanto, com relação ao milho-verde, o volume de sementes comercializadas para esta finalidade é baixo, e, em alguns casos, o produtor utiliza sementes destinadas a grão e com doses inferiores de nitrogênio, por apresentar um período mais curto até à colheita. Dessa forma, o objetivo do trabalho foi avaliar o desempenho de dois híbridos de milho, destinados a grão, colhidos verdes e comparados a um híbrido destinado a este mercado, em diferentes doses de nitrogênio. O experimento foi realizado durante a safra de 2011/2012, utilizando delineamento experimental de blocos casualizados, em esquema fatorial $3 \times 5$ (três híbridos de milho em cinco doses de nitrogênio), com três repetições. Foram utilizados os híbridos DKB175, P30F53Y e o AG1051 (controle), sob as doses de 0; 40; 80; 120 e $160 \mathrm{~kg} \mathrm{ha}^{-1}$ de $\mathrm{N}$, sendo analisadas as características agronômicas de altura da planta, produtividade de espigas empalhadas, despalhadas e comerciais, comprimento e diâmetro de espigas comerciais, no estádio de $\mathrm{R}_{3}$ (grão leitoso). Os dados obtidos foram submetidos à análise de variância e regressão, e os resultados mostram que o híbrido P30F53Y apresenta melhor desempenho, quando comparado ao DKB175, e semelhante ao controle. A dose a ser utilizada pelo produtor está relacionada com a forma de comercialização das espigas, visando ao consumo in natura. A produtividade máxima de espigas empalhadas e comerciais é obtida nas doses de 143 e $160 \mathrm{~kg} \mathrm{ha}^{-1}$ de N para o híbrido P30F53Y, e 93 e $99 \mathrm{~kg} \mathrm{ha}^{-1}$ para o híbrido DKB175.

Palavras-chave adicionais: espigas comerciais; espigas empalhadas; milho-verde; Zea mays L.

\begin{abstract}
Brazil is a great corn producer but vegetable corn production is still very low. Seed production specifically for vegetable corn is very low so that frequently the producers make use of grain seeds to plant their fields, making use of lower nitrogen doses since the plant cycle will be shortened. The objective of this study was to evaluate the performance of two grain corn hybrids in comparison with that of a vegetable corn hybrid. The experiment took place during the crop year of 2011/12 in a randomized complete block design in a $3 \times 5$ factorial scheme (three corn hybrids and five nitrogen doses) with three replications. The hybrids DKB175, P30F53Y, and AG1051 (check treatment) were grown under the doses of 0,40, 80,120, and $160 \mathrm{~kg} \mathrm{ha}^{-1}$ of $\mathrm{N}$. The agronomic characteristics plant height, yield of unhusked, husked, and marketable ears, length and diameter of marketable ears at stage R3 (milky stage) were evaluated. The data were submitted to the variance and regression analyses. The results show that the hybrid P30F53Y had the best performance in comparison to DKB175 and a similar performance in comparison with the check treatment. The dose to be used by the producer depends on the way the ears will be commercialized, having in mind the in natura consumption. The maximum yield of husked and commercial ears results from the doses of 143 and $160 \mathrm{~kg} \mathrm{ha}^{-1}$ of $\mathrm{N}$ for the hybrid P30F53Y and of 93 and $99 \mathrm{~kg} \mathrm{ha}^{-1}$ of $\mathrm{N}$ for the hybrid DKB175.
\end{abstract}

Additional keywords: commercial ears; unhusked ears; vegetable corn; Zea may L. 


\section{Introdução}

Segundo estudos das projeções de produção do milho, realizados pela Assessoria de Gestão Estratégica do Ministério da Agricultura, Pecuária e Abastecimento - MAPA, indicam um aumento de 19,11 milhões de toneladas entre a safra de 2008/2009 e 2019/2020 (MAPA, 2012). Esses resultados demonstram que o Brasil deverá fazer ajustes no abastecimento e melhorar sua produtividade média para garantir o abastecimento do mercado interno e, ainda, obter excedente para exportação. Entretanto, apesar da importância da cultura e do mercado crescente por causa do crescimento populacional, sua produtividade ainda é considerada baixa, uma vez que o potencial produtivo da cultura é de $19.113 \mathrm{~kg} \mathrm{ha}^{-1}$ (Assis et al., 2006) e a produtividade média brasileira está em torno $5.000 \mathrm{~kg} \mathrm{ha}^{-1}$, na safra de 2013/2014, valor considerado muito abaixo do que é possível de se obter (CONAB, 2014).

Os programas de melhoramento das empresas privadas e públicas são dinâmicos e disponibilizam um elevado número de sementes e, claro, de diferentes bases genéticas, com o intuito de atender a maioria dos produtores brasileiros e dos mais diversos níveis tecnológicos (Hanashiro et al., 2013). Entretanto, o número de cultivares destinadas à produção de milho-verde é baixa, existindo 467 cultivares disponíveis no mercado para a safra de $2013 / 2014$ e somente $4 \%$ destas destinadas a tal finalidade (Cruz, 2014). Além disso, somente 12 cultivares são indicadas para a região Centro-Oeste, o que dificulta ainda mais a obtenção de altas produtividades, devido à interação genótipo $x$ ambiente. Outro entrave é o nível tecnológico a ser adotado pelo produtor, normalmente de médio a alto, denotando que são necessárias doses específicas dos nutrientes, para que a planta expresse todo o seu potencial produtivo.

$\mathrm{O}$ nitrogênio $(\mathrm{N})$ é o nutriente mais exigido pela cultura do milho, e o suprimento inadequado é considerado um dos principais fatores limitantes ao crescimento e rendimento de grãos; assim, plantas supridas adequadamente com $\mathrm{N}$ terão bom desenvolvimento radicular e, consequentemente, melhor produtividade (Silva et al., 2013). Todavia, produtores excedem o que é recomendado pelas empresas ou fazem a aplicação dos nutrientes sem uma análise prévia do solo, gerando um custo de produção elevado e acarretando diminuição do potencial genético das cultivares. Ou seja, não consideram as perdas por lixiviação, volatilização e, ainda, o risco da poluição ambiental, tanto dos rios por eutrofização ou até mesmo do ar pela formação de gases (Gao et al., 2014). Vários estudos alertam sobre o excesso da adubação, e modelos matemáticos demonstram que, em pouco tempo, rios e mares terão uma redução drástica das populações aquáticas em várias bacias hidrográficas e que, em poucos países, a situação está sendo controlada (Lee et al., 2014; Yang et al., 2014).
Estudos sobre o comportamento de cultivares destinadas a região Centro-Oeste, mas com possibilidade de utilização para o consumo in natura, são de grande importância para os produtores locais, que podem aliar preço de mercado com o potencial produtivo da cultivar para grãos e, possivelmente, para milho-verde. Além disso, outro fator importante a considerar seria a redução da adubação nitrogenada aliada à diminuição dos custos de produção e diminuição dos problemas causados pelo uso de $\mathrm{N}$ em excesso. Informações a esse respeito poderiam contribuir para a decisão da cultivar a ser utilizada e do produto a ser comercializado, visto que os híbridos já possuem alto potencial produtivo para grãos (Hanashiro et al., 2013; Guadagnin et al., 2011), além de obter informações sobre doses de $\mathrm{N}$ a ser adotadas para essas cultivares, para obter a máxima produtividade econômica, quando colhidos para o consumo in natura, visando ao mercado de milho-verde.

Dessa forma, o objetivo deste trabalho foi avaliar o desempenho de dois híbridos de milho, DKB175 e o P30F53Y, colhidos verdes, sob diferentes doses de adubação nitrogenada quando comparados ao AG1051 (Controle), relatando a possibilidade de utilização desses híbridos para o consumo in natura e a dose ideal para essa finalidade.

\section{Material e métodos}

O solo da região é composto por Latossolo Vermelho-Amarelo distrófico, conforme os critérios descritos em EMBRAPA (2006), no qual os dados da análise química estão apresentados na Tabela 1. A região apresenta clima tropical úmido, com duas estações bem definidas, seca e chuvosa, sendo o experimento instalado sobre a chuvosa, sendo semeado no dia 25 de outubro, no município de Ipameri-GO.

Foram utilizados dois híbridos destinados à região Centro-Oeste de Goiás; o híbrido DKB175 e o híbrido P30F53Y, ambos com elevado potencial produtivo, precoce e de elevada estabilidade e adaptabilidade em vários ambientes (Tabela 2). Além destes, o híbrido AG1051, como controle, é indicado para o mercado de milho-verde, possuindo espigas de excelente qualidade e boa produtividade de espigas empalhadas.

O delineamento experimental utilizado foi o de blocos casualizados, com três repetições, no arranjo fatorial de $3 \times 5$ (três híbridos em cinco doses de nitrogênio), em que cada parcela foi constituída por quatro fileiras, com quatro metros de comprimento, e espaçadas em 0,5 metro, com três plantas por metro linear, utilizando-se somente das duas fileiras centrais, totalizando uma área útil de $4 \mathrm{~m}^{2}$.

Foram aplicados $900 \mathrm{~kg}$ de calcário dolomítico com PRNT de $70 \%$, incorporado na camada de 0-20. Após o período de 25 dias, iniciou-se o preparo do solo, sendo realizado de maneira convencional com uma aração e duas gradagens, onde se utilizou um cultivador para a abertura dos sulcos de plantio. 
Tabela 1 - Atributos químicos do solo $(0 \mathrm{a} 20 \mathrm{~cm}$ de profundidade) antes da instalação do experimento. Chemical attributes of the soil ( 0 to $20 \mathrm{~cm}$ depth) before experiment installation.

\begin{tabular}{|c|c|c|c|c|c|c|c|c|c|}
\hline $\mathrm{pH}$ & M.O. & Presina & $\mathrm{H}^{+}+\mathrm{Al}^{+3}$ & $\mathrm{~K}^{+}$ & $\mathrm{Ca}^{+2}$ & $\mathrm{Mg}^{+2}$ & SB & \multirow[t]{2}{*}{ СтC } & \multirow{2}{*}{$\begin{array}{l}\mathrm{V} \% \\
(\%)\end{array}$} \\
\hline $\mathrm{CaCl}_{2}$ & $\left(\mathrm{~g} \mathrm{dm}^{-3}\right)$ & $\left(\mathrm{mg} \mathrm{dm}^{-3}\right)$ & & - & --- $(\mathrm{mn}$ & $\left.\mathrm{dm}^{-3}\right)$ & - & & \\
\hline 4,9 & 24,1 & 9,0 & 30,3 & 4,1 & 18,2 & 7,5 & 27,8 & 57,6 & 47,7 \\
\hline
\end{tabular}

Metodologias descritas em SILVA (1999); pH - acidez ativa; M.O. - Matéria orgânica; P - Fósforo disponível; $\mathrm{H}+\mathrm{Al}$ - acidez potencial; $\mathrm{k}$ - Potássio disponível; $\mathrm{Ca}$ - Cálcio trocável; $\mathrm{Mg}$ - Magnésio trocável; SB - Soma de bases trocáveis; CTC - Capacidade de troca catiônica efetiva; V\% - Saturação por bases.

Tabela 2 - Características dos híbridos comerciais que foram avaliados no experimento, visando ao consumo in natura. Characteristics of the commercial hybrids used in the experiment aming in natura consumption.

\begin{tabular}{lllllccc}
\hline Cultivar & $\begin{array}{l}\text { Transgênica/ } \\
\text { Convencional }\end{array}$ & Tipo & Ciclo & Uso & Cor do grão & $\begin{array}{c}\text { Altura da planta } \\
(\mathrm{m})\end{array}$ & Nível de tecnologia \\
\hline AG 1051 & Convencional & HD & SMP G/SPI/MV & AM & 2,60 & M/A \\
DKB 175 & Convencional & HS & P & G & AM/AL & 2,20 & A \\
P 30F53 Y & Transgênica & HS & P & G & AL & 2,70 & A \\
\hline
\end{tabular}

Cruz (2014); Tipo: HD - híbrido duplo, HS - híbrido simples; Ciclo: P - precoce, SMP - semiprecoce; Uso: G - Grãos; SPI - silagem de planta inteira, MV - milho-verde; Cor do grão: AL - Alaranjado, AM - Amarelo; Nível de tecnologia: A - Alto, M - Médio.

As adubações de plantio e de cobertura foram realizadas conforme as recomendações de adubação para cultura de milho-verde, visando a produtividade entre 15.000 e $17.000 \mathrm{~kg} \mathrm{ha}^{-1}$ de milho-verde empalhado $\left(120 \mathrm{~kg} \mathrm{ha}{ }^{-1}\right.$ de $\mathrm{P}_{2} \mathrm{O}_{5}$ e $90 \mathrm{~kg}$ ha $^{-1}$ de $\mathrm{K}_{2} \mathrm{O}$ ), conforme Pereira Filho (2003), variando apenas as doses de nitrogênio para cada tratamento, onde foram aplicados 0; 40; 80; 120 e 160 $\mathrm{kg} \mathrm{ha}^{-1}$ de $\mathrm{N}$, parcelados em duas doses equitativas, sendo uma na semeadura, no sulco de plantio, e outra trinta dias após a semeadura, em cobertura, próximo à linha, no estádio $\mathrm{V} 3$, utilizando-se de ureia $(45 \%$ de $\mathrm{N})$.

Foram realizadas aplicações de produtos fitossanitários para o controle da lagarta-do-cartucho, mediante 0 monitoramento, sendo utilizados metoxifenozida $240 \mathrm{~g} \mathrm{~L}^{-1}$ (Intrepid ${ }^{\circledR}$ ), na dose de 150 $\mathrm{mL} \mathrm{ha}^{-1}$, no estádio V3, e beta-cipermetrina (Akito ${ }^{\circledR}$ ), na dose de $75 \mathrm{~mL} \mathrm{ha}^{-1}$, no estádio $\mathrm{V} 5$, aliados a capinas manuais, realizadas a cada 3 semanas.

A colheita foi realizada manualmente, à medida que as espigas atingiam o ponto de estádio leitoso (R3), ou seja, quando os grãos das espigas das plantas de cada parcela estavam com 70 a $80 \%$ de teor de água, considerado o ponto ideal para a comercialização in natura, aproximadamente 90 dias após o plantio.

Foram avaliadas as características: AP altura da planta, na qual foi realizada a medição das plantas, após o florescimento feminino, obtendo-se a altura de seis plantas representativas da área útil de cada parcela, em $\mathrm{cm}$, da região do colo da planta até o pendão; PEE - produtividade de espigas empalhadas, que foi obtida pela soma do peso total das espigas com palha na área útil de cada parcela, posteriormente transformados para toneladas por hectare; PED - produtividade de espigas despalhadas, que foi obtida pela soma do peso das espigas despalhadas de cada parcela, posteriormente transformados para toneladas por hectare; PEC - produtividade de espigas comerciais, que foi obtida pela soma do peso das espigas despalhadas maiores que $15 \mathrm{~cm}$ e com diâmetro superior a $3 \mathrm{~cm}$ e, também, isentas de pragas e doenças; COMP - comprimento médio das espigas comerciais, no qual se mediu o comprimento de cinco espigas comerciais, tomadas ao acaso em cada parcela, sendo a média aritmética dessas espigas atribuída à parcela; DIAM - diâmetro médio das espigas comerciais, no qual foi medido, com o auxílio de um paquímetro, o diâmetro médio de cinco espigas comerciais tomadas ao acaso em cada parcela, sendo atribuída a média aritmética do diâmetro à parcela, conforme Rodrigues et al. (2009).

Inicialmente, o experimento foi analisado de acordo com o modelo estatístico:

$Y_{i j q}=m+g_{i}+a_{q}+b_{(q) j}+(g a)_{i j}+e_{(q) j i j}$ em que: $Y_{i j}$ - observação do híbrido i no bloco j dentro da dose q; $m$ - média geral; $g_{i}$ - efeito do i-ésimo híbrido; $a_{q}$ - efeito da dose $q-b_{(q) j}$ : efeito do j-ésimo bloco dentro da dose q; (ga)ij: - efeito da interação entre os híbridos $\mathrm{i}$ e as doses q; $\mathrm{e}_{(\mathrm{q}) \mathrm{jij}}$ : - erro experimental. Posteriormente foi realizada a regressão dos dados e o teste de média, a $5 \%$ de probabilidade, pelo método de Scott Knott, utilizando o programa computacional Genes (Cruz, 2006).

\section{Resultados e discussão}

O resultado da análise de variância está apresentado na Tabela 3, podendo-se verificar que, para a maioria das características estudadas, houve 
diferença significativa $(p \leq 0,05)$. Para a fonte de variação Híbridos, exceto para altura de planta (AP), e para a fonte Híbridos $x$ Doses, as características $\mathrm{AP}$, comprimento de espigas comerciais (COMP) e diâmetro médio de espigas comerciais (DIAM), não foram significativas, permitindo-se afirmar que os híbridos apresentaram comportamentos semelhantes nas diferentes doses testadas.

Tabela 3 - Teste F para altura da planta (AP), produtividade de espigas empalhadas (PEE), produtividade de espigas despalhadas (PED), produtividade de espigas comerciais (PEC), comprimento médio de espigas comerciais (COMP) e diâmetro médio de espigas comerciais (DIAM), em diferentes híbridos de milho, utilizando cinco doses de nitrogênio $\left(0 ; 40 ; 80 ; 120\right.$ e $160 \mathrm{~kg} \mathrm{ha}^{-1}$ de $\left.N\right)$, visando ao consumo in natura. $F$ test results for plant height (AP), yield of unhusked ears (PEE), yield of husked ears (PED), yield of commercial ears (PEC), mean length of commercial ears (COMP), and mean diameter of commercial ears (DIAM) for different corn hybrid plants growing under five nitrogen levels aming in natura consumption.

\begin{tabular}{|c|c|c|c|c|c|c|c|}
\hline \multirow[b]{2}{*}{ Fonte } & \multicolumn{6}{|c|}{ Características } & \multirow[b]{2}{*}{$\begin{array}{l}\text { DIAM } \\
\text { (cm) }\end{array}$} \\
\hline & $\mathrm{GL}$ & $\begin{array}{l}\text { AP } \\
(\mathrm{cm})\end{array}$ & $\begin{array}{c}\text { PEE } \\
\left(\mathrm{kg} \mathrm{ha}^{-1}\right)\end{array}$ & $\begin{array}{c}\text { PED } \\
\left(\mathrm{kg} \mathrm{ha}^{-1}\right)\end{array}$ & $\begin{array}{c}\text { PEC } \\
\left(\mathrm{kg} \mathrm{ha}^{-1}\right)\end{array}$ & $\begin{array}{l}\text { COMP } \\
(\mathrm{cm})\end{array}$ & \\
\hline Híbridos $(\mathrm{H})$ & 2 & $107,4^{\text {n.s. }}$ & $5.059 .894,7^{* \star}$ & $2.768 .202,6^{* *}$ & $1.408 .809,5^{\star *}$ & $26,2^{\star *}$ & $1,2^{* *}$ \\
\hline Doses (D) & 4 & $3.178,6^{*}$ & $1.387 .555,5^{\star *}$ & $440.273,6^{* *}$ & $389.123,6^{* *}$ & $25,3^{\star *}$ & $2,4^{\star}$ \\
\hline$H \times D$ & 8 & $220,6^{\text {n.s. }}$ & $332.929,5^{\star \star}$ & $223.702,4^{* *}$ & $102.759,1^{*}$ & $2,3^{\text {n.s. }}$ & $0,2^{\text {n.s. }}$ \\
\hline Bloco & 2 & 806,6 & $379.837,5$ & $153.923,6$ & $146.963,3$ & 3,9 & 0,2 \\
\hline Erro & 28 & 81,3 & $41.734,4$ & $26.080,1$ & $35.675,4$ & 2,2 & 0,1 \\
\hline CV\% & & 9,4 & 9,3 & 10,6 & 14,7 & 8,9 & 5,6 \\
\hline
\end{tabular}

Dentre os nutrientes, o nitrogênio destaca-se como o nutriente absorvido em maior quantidade pelo milho; dessa forma, influência sobre o rendimento do grão e, consequentemente, sobre a produtividade dos híbridos, como observado na Tabela 3 , na fonte Híbridos x Doses, principalmente por estar relacionado aos mais importantes processos fisiológicos que ocorrem na planta, tais como: fotossíntese, respiração, desenvolvimento, atividades das raízes, absorção iônica de outros nutrientes, crescimento e diferenciação celular e, claro, no potencial genético (Yamada, 1997). No entanto, encontrase em quantidades insuficientes na maioria dos solos brasileiros, demandando uma fertilização em doses adequadas para garantir o desenvolvimento e a produtividade do milho (Belarmino et al., 2003).

Os valores do coeficiente de variação (CV\%) corroboram os obtidos por Rodrigues et al. (2009), avaliando a capacidade geral de combinação (CGC) e a capacidade específica de combinação (CEC) em híbridos e linhagens endogâmicas, visando à produção de híbridos simples de milhoverde, variando entre 8,4 e $20,7 \%$, entre as características de altura de planta e produtividade de espigas comerciais, respectivamente. Valor superior de CV\% para produtividade de espigas comerciais

(PEC) foi observado por Souza et al. (2013), avaliando os componentes da produção e a composição de grãos de híbridos de milho-doce, com valor de 18\%.

Verifica-se que os híbridos apresentaram AP de $195 \mathrm{~cm}$, conforme Tabela 4, indicando a possibilidade de utilização da massa fresca como silagem, visto que a maioria dos híbridos destinados à produção de milho-verde disponibilizados no mercado, atualmente, possuem também a aptidão para este uso (Tabela 2). Segundo Neumann et al. (2005), as doses de 0; 45; 90 e $135 \mathrm{~kg}$ de N ha-1 promovem 194; 201; 214 e $203 \mathrm{~cm}$, respectivamente, para a altura de plantas. Entretanto, não promovem incrementos significativos nos componentes de produção de plantas de milho, em função das doses de adubação nitrogenada em cobertura, confirmando que o nitrogênio não terá grande influência sobre a silagem formada, quando utilizada a planta inteira. Entretanto, os autores fazem uma ressalva com relação às condições da safra e que tais resultados podem estar relacionados com estresse hídrico, ocasionado pelo déficit hídrico, devido aos veranicos, como os que ocorreram neste experimento e, assim, apresentarem alta relação com a condição da safra avaliada.

Tabela 4 - Média das características de altura da planta (AP), comprimento médio de espigas comerciais (COMP) e diâmetro médio de espigas comerciais (DIAM), em diferentes híbridos de milho, utilizando cinco doses de adubação nitrogenada (0;40;80; 120 e $160 \mathrm{~kg} \mathrm{ha}^{-1}$ de N). Plant height (AP), commercial ears length (COMP), and commercial ears diameter (DIAM) of different corn hybrid plants growing under five nitrogen levels having in mind in natura consumption.

\begin{tabular}{lccc}
\hline Híbridos & $\begin{array}{r}\text { AP } \\
(\mathrm{cm})\end{array}$ & $\begin{array}{c}\text { COMP } \\
(\mathrm{cm})\end{array}$ & $\begin{array}{c}\text { DIAM } \\
(\mathrm{cm})\end{array}$ \\
\hline AG1051 $(\mathrm{T})$ & $189,1 \mathrm{a}$ & $18,1 \mathrm{a}$ & $4,7 \mathrm{a}$ \\
DKB175 & $185,9 \mathrm{a}$ & $15,5 \mathrm{~b}$ & $4,3 \mathrm{~b}$ \\
P30F53Y & $210,8 \mathrm{a}$ & $16,2 \mathrm{~b}$ & $4,8 \mathrm{a}$ \\
\hline Média & 195,3 & 16,6 & 4,6 \\
\hline
\end{tabular}

Médias seguidas pela mesma letra na vertical não diferem entre si, pelo teste de Scott Knott, a $5 \%$ de probabilidade; $\mathrm{T}$ - Testemunha comercial de milho-verde. 
Segundo dados da CONAB (2014), sobre o monitoramento agrícola no sul Goiano, houve irregularidades no período de chuvas da região, principalmente no mês de janeiro, em comparação à precipitação ocorrida nas safras de 2012/2013, e no histórico dos últimos dez anos; dessa forma, os resultados apresentaram valores de produtividade e demais componentes da produção, abaixo do esperado.

O mercado consumidor de milho-verde é exigente com relação a características fenotípicas da espiga, onde durante um período curto de tempo, este se torna altamente perecível; assim, espigas que agradam mais o consumidor terão um tempo menor de prateleira. Estas características estão relacionadas ao comprimento (COMP) e diâmetro das espigas (DIAM), respectivamente. Detecta-se que os híbridos apresentaram padrões comerciais; todavia, o P30F53Y e DKB175, em comparação com a testemunha, obtiveram desempenho significativo e inferior para COMP, e semelhante para DIAM no P30F53Y (Tabela 4).

Carmo et al. (2012) observaram que diâmetro do colmo, altura de inserção de espiga, diâmetro do sabugo e comprimento de espiga apresentavam comportamento linear ao aumento das doses de $\mathrm{N}$, com aplicações de 0; 50; 100 e $150 \mathrm{~kg} \mathrm{ha}^{-1}$ de $\mathrm{N}$, sendo estes valores bem próximos aos aplicados neste experimento: entretanto, sob sistema de irrigação de pivô central, que promove melhor distribuição de água e sem déficit hídrico durante a condução do mesmo, dessa forma promove melhor desempenho produtivo, quando comparado ao cultivo sem o uso da irrigação.

$\mathrm{Na}$ Figura 1, os híbridos AG1051 e P30F53Y apresentaram comportamento significativo ao aumento das doses. As doses acima de $150 \mathrm{e}$ $143 \mathrm{~kg} \mathrm{ha}^{-1}$ de $\mathrm{N}$, respectivamente, não promovem incrementos significativos na PEE destes híbridos. Além disso, o híbrido DKB175 apresentou desempenho inferior quando comparado aos híbridos citados, no qual doses acima de $93 \mathrm{~kg} \mathrm{ha}^{-1}$ de $\mathrm{N}$ não contribuíram para o incremento da produtividade. A média da PEE mesmo sob as doses de $40 \mathrm{~kg}^{\mathrm{h}} \mathrm{ha}^{-1}$ de $\mathrm{N}$, foi superior à citada na literatura, na qual DoVale et al. (2011) obtiveram média de $4.400 \mathrm{~kg} \mathrm{ha}^{-1}$, avaliando dez cultivares comerciais de milho, visando ao consumo fresco, e inferiores às obtidas por Rodrigues et al. (2011), avaliando híbridos e linhagens experimentais de milho-verde.

De acordo com o preço médio pago na CEASAMINAS (2014) e na CEAGESP (2014), utilizando a máxima produtividade obtida por híbrido, em suas respectivas doses, descritas anteriormente, a renda bruta obtida pela venda das espigas empalhadas no híbrido P30F53Y seria apenas 2\% inferior ao AG1051. Em comparação com o DKB175, esse valor chega a $46 \%$, acarretando perda significativa para 0 produtor (Figura 1), confirmando o potencial do AG1051 para este nicho de mercado e, também, a possibilidade de utilização do P30F53Y para esta finalidade.

De acordo com os resultados obtidos por Paiva et al. (2012), avaliando diferentes doses de $\mathrm{N}$ e fósforo $(P)$ combinadas, visando à máxima produção econômica de milho-verde, utilizando o híbrido AG1051 em solo alcalino, relataram que a dose adequada de $\mathrm{N}$ para o máximo rendimento é de $60 \mathrm{~kg} \mathrm{ha}^{-1}$ quando combinada com $106 \mathrm{~kg} \mathrm{ha}^{-1}$ de $\mathrm{P}_{2} \mathrm{O}_{5}$. Ou seja, valor abaixo do aplicado neste experimento para $P$, neste caso, $120 \mathrm{~kg} \mathrm{ha}^{-1}$ de $\mathrm{P}_{2} \mathrm{O}_{5}$, indicando que a produtividade não foi comprometida pela ausência de $\mathrm{P}$ no solo, entretanto valor bem abaixo para N. Observa-se, na Figura 1, que a produtividade estaria seriamente comprometida se fosse usado este valor para a produção comercial, principalmente para o AG1051, no qual produziria apenas $7.700 \mathrm{~kg} \mathrm{ha}^{-1}$ se aplicado este valor, e $9.700 \mathrm{~kg} \mathrm{ha}^{-1}$, se aplicados os mesmos $60 \mathrm{~kg} \mathrm{ha}^{-1}$ de $\mathrm{N}$.

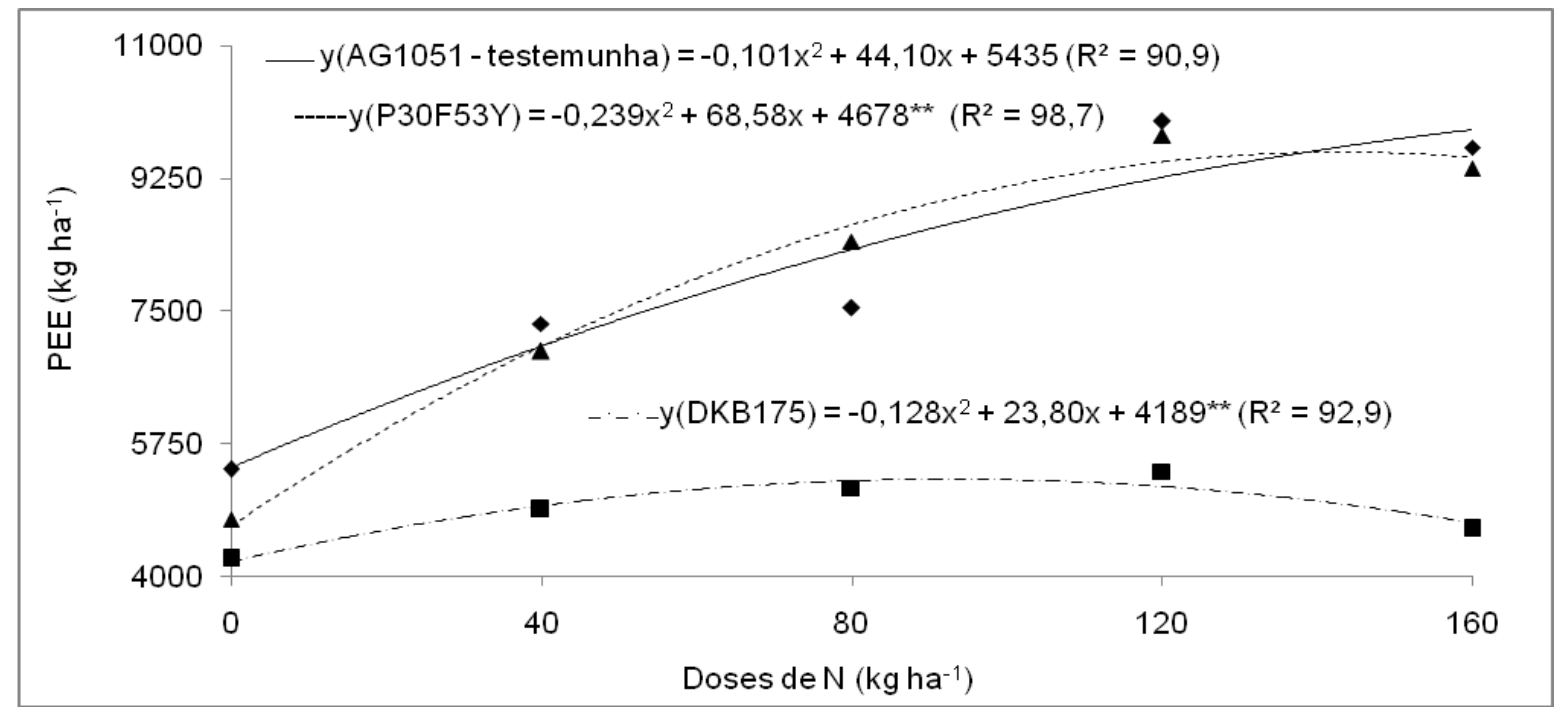

Figura 1 - Produtividade de espigas empalhadas (PEE), em função de diferentes híbridos de milho e dose de N. Unhusked ears productivity (PEE) of corn hybrids plants grown under different nitrogen doses. 
Observa-se que, para a característica PED, houve comportamento quadrático dos híbridos e que os valores das doses diminuem quando são retiradas as palhas, sendo o máximo rendimento econômico obtido em torno de 153 e $138 \mathrm{~kg} \mathrm{ha}^{-1}$ de $\mathrm{N}$, respectivamente, para os híbridos AG1051 e P30F53Y, com valores de produtividade médios em torno de $6.500 \mathrm{~kg} \mathrm{ha}^{-1}$, e para o híbrido DKB175, com $73 \mathrm{~kg} \mathrm{ha}^{-1}$ de N, com produtividade média em $4.200 \mathrm{~kg} \mathrm{ha}^{-1}$ (Figura 2). É importante ressaltar que o excesso de palha traz uma série de benefícios para o agricultor, como melhor proteção da espiga, importante para o transporte, e também maior quantidade de silagem. Avaliando o desempenho de oito cultivares de milho-verde na safrinha, no Estado de São Paulo, Moraes et al. (2010) obtiveram média de espigas despalhadas em $4.819 \mathrm{~kg} \mathrm{ha}^{-1}$, e $\mathrm{o}$ híbrido AG1051 apresentou produtividade média de $4.824 \mathrm{~kg} \mathrm{ha}^{-1}$, valor este obtido com a aplicação de apenas $20 \mathrm{~kg} \mathrm{ha}^{-1}$ de $\mathrm{N}$, indicando que o híbrido é responsivo ao aumento das doses, assim como o P30F53Y (Figura 2).

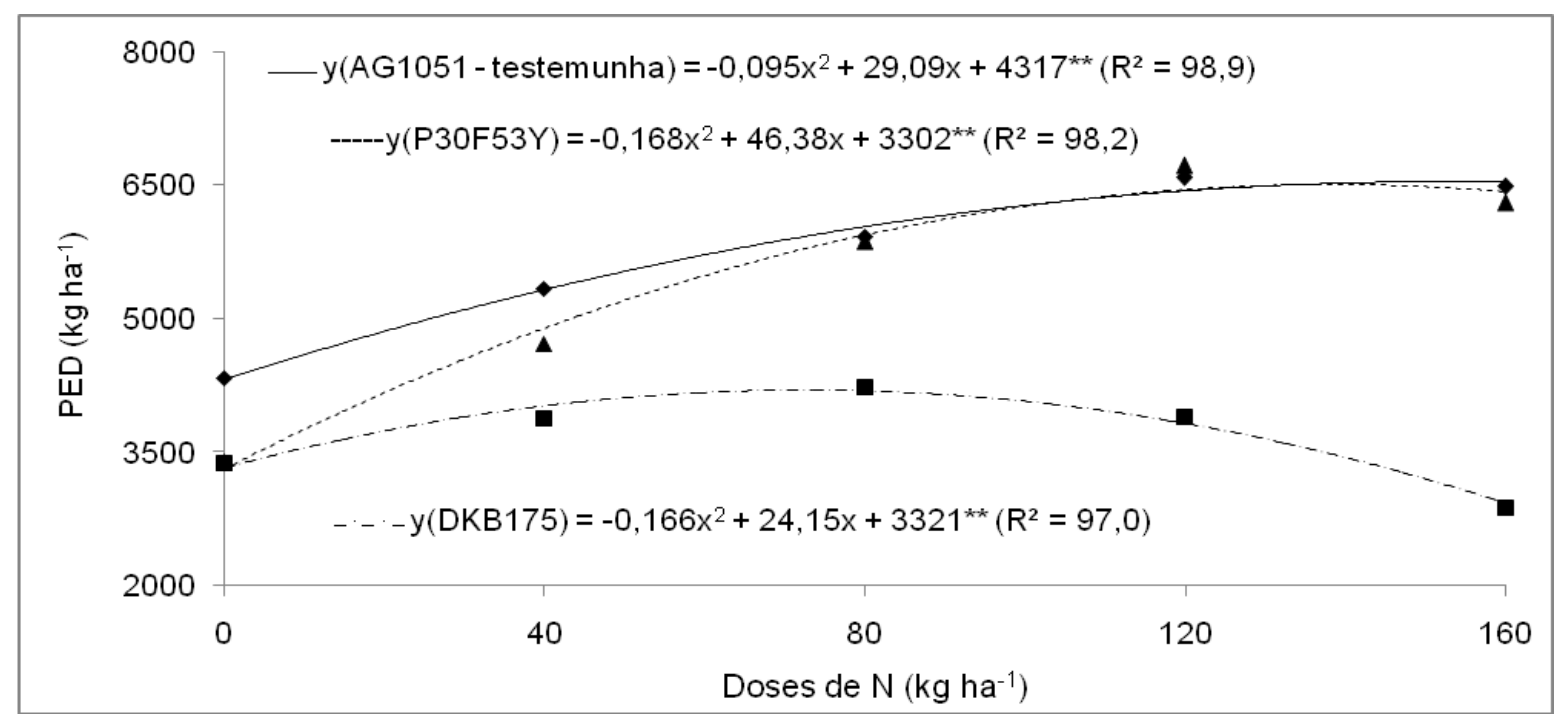

Figura 2 - Produtividade de espigas despalhadas (PED), em função de diferentes híbridos de milho e dose de N. Corn hybrids productivity of husked ears (PED) under different doses of $N$.

A produtividade de grãos da cultura de milho dependente diretamente da atividade fotossintética da planta, sendo que a fotossíntese depende da área foliar e do tempo de permanência das folhas em plena atividade na planta (Fancelli \& Dourado Neto, 2000), que, por sua vez, dependem do estado nutricional da planta. Em contrapartida, nas adubações nitrogenadas, é importante que a quantidade de $\mathrm{N}$ a ser aplicada na cultura do milho seja a mais exata possível, minimizando tanto os excessos, que prejudicam a qualidade ambiental e oneram o produtor (Silva et al., 2007), quanto as quantidades deficientes, que podem comprometer a produtividade esperada.

Além disso, os nutrientes em excesso nos efluentes, especialmente o nitrogênio, podem resultar em problemas ambientais, principalmente por sua lixiviação e pela contaminação do lençol freático, uma vez que os mananciais subterrâneos e os corpos d'água superficiais são os receptores finais das águas lançadas sobre o solo. Dessa forma, percebe-se que o produtor deve selecionar a dose a ser aplicada de acordo com a venda do produto, ou seja, se as espigas são vendidas empalhadas, doses elevadas favorecem o aumento da PEE, não sendo possível avaliar se as espigas apresentam má-formação ou mesmo fileiras deficientes e mesmo assim podem ser comercializadas. Entretanto, se o produtor realizar a venda de forma despalhada, grande parte das espigas não poderão ser comercializadas, por não se adequarem aos padrões de comercialização do mercado.

O híbrido AG1051 apresentou incremento significativo para PEE até doses de $150 \mathrm{~kg} \mathrm{ha}^{-1}$ de $\mathrm{N}$, com valores de $9.777 \mathrm{~kg} \mathrm{ha}^{-1}$, promovendo o melhor retorno financeiro ao produtor. Mas se fosse aplicada a mesma dose supracitada anteriormente para PEE e a venda fosse realizada por espigas comerciais (PEC), o produtor estaria aplicando $33 \mathrm{~kg} \mathrm{ha}^{-1}$ de $\mathrm{N}$ a mais para este híbrido. Todavia, o mesmo valor poderia ser mantido para o DKB175 e, para o híbrido P30F53Y, a dose deveria ser aumentada em $17 \mathrm{~kg} \mathrm{ha}^{-1}$ de $\mathrm{N}$, visando ao aumento no número de espigas comerciais e maior lucratividade (Figura 3).

Soratto et al. (2012) relataram que os adubos com inibidores de nitrificação apresentam melhores resultados que a ureia em milho, na safrinha; assim, parte da produtividade de espigas comerciais pode ter sido reduzida pela perda de $\mathrm{N}$ por volatilização e, ainda, devido à cultura do ciclo anterior. Neste caso, o milho-verde, com a retirada dos restos vegetais, diminui drasticamente a quantidade de nutrientes para os próximos plantios. Além disso, a forma e a época do parcelamento podem influenciar nos resultados de produtividade, como observado por Zucareli et al. (2014), em estudos 
também realizados na safrinha, utilizando diferentes doses de $\mathrm{N}$, em combinações com estádios de desenvolvimento, utilizando ureia e sulfato de amônio. Dessa forma, devem ser combinados híbridos mais responsivos ao nitrogênio e, também, adubos minerais mais eficientes na disponibilização do $\mathrm{N}$ para as plantas, aliados com a forma comercialização das espigas, visando a maior lucratividade para o produtor e a menor dano ao meio ambiente.

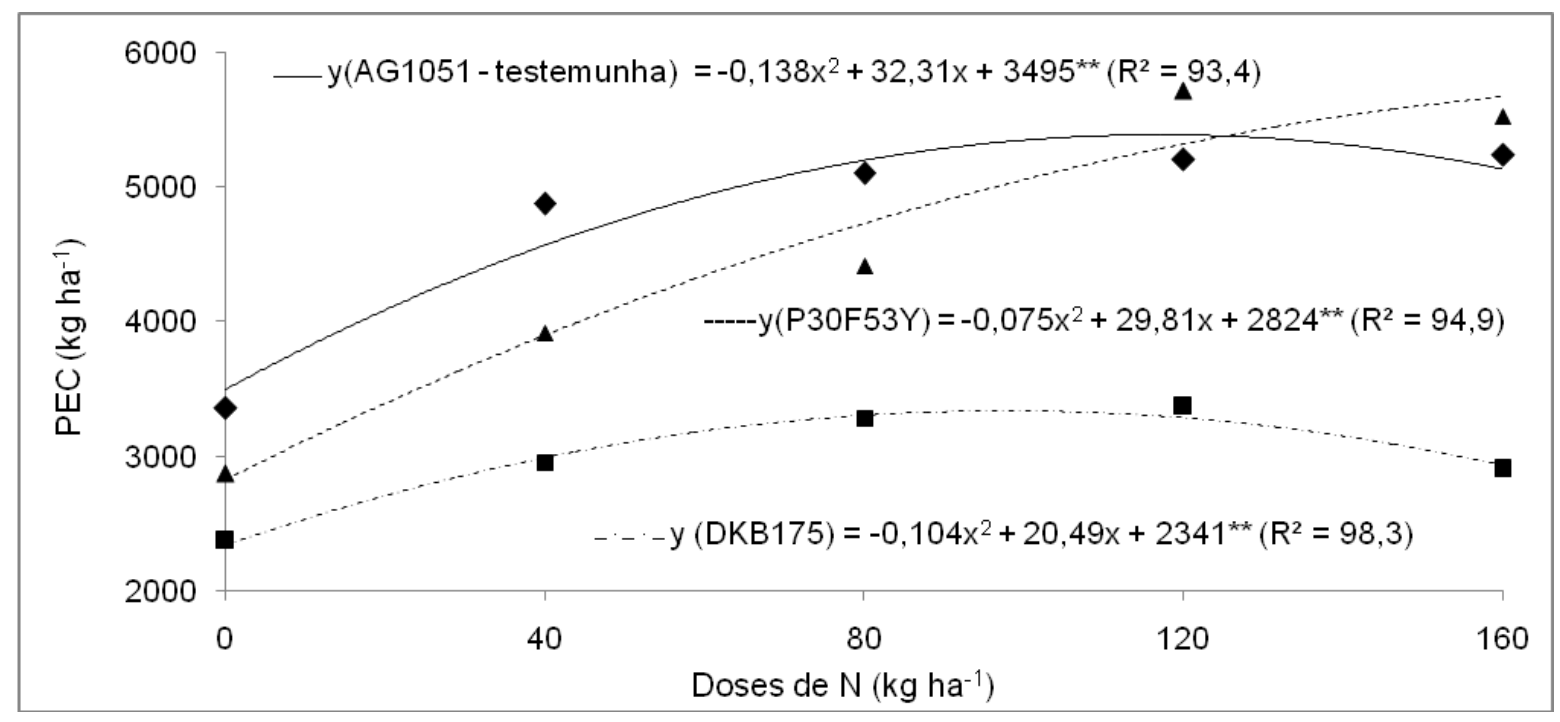

Figura 3 - Produtividade de espigas comerciais (PEC), em função de diferentes híbridos de milho e dose de $\mathrm{N}$. Yield of commercial ears (PEC), for different corn hybrids and $N$ doses.

\section{Conclusões}

O híbrido P30F53Y apresentou melhor desempenho para a produção de espigas comerciais, e similar ao AG1051 para espigas empalhadas e despalhadas, podendo ser indicado para o mercado de milho-verde.

A dose a ser utilizada pelo produtor está relacionada com a forma de comercialização das espigas, visando ao consumo in natura, sendo a produtividade máxima de espigas empalhadas e comerciais obtida nas doses de 143 e $160 \mathrm{~kg} \mathrm{ha}^{-1}$ de $\mathrm{N}$ para o híbrido P30F53Y, 150 e $117 \mathrm{~kg}$ para o AG1051 e 93 e 99 kg para o híbrido DKB175.

\section{Referências}

Assis JPD, Dourado Neto D, Nass LL, Manfron PA, Bonnecarrère RAG, MARTIN TN (2006) Simulação estocástica de atributos do clima e da produtividade potencial de milho utilizando-se de distribuição triangular. Pesquisa Agropecuária Brasileira. 41(3):539-543.

Belarmino MCJ, Pinto JC, Rocha GP, Furtini Neto AE Morais AR (2003) Altura de perfilho e rendimento de matéria seca de capim-tanzânia em função de diferentes doses de superfosfato simples e sulfato de amônio. Ciência e Agrotecnologia. 27(4):879-885.

Carmo MS, Cruz SCS, Souza EJ, Campos LFC, Machado CG (2012) Doses e fontes de nitrogênio no desenvolvimento e produtividade de milho doce (Zea mays convar. saccharata var. rugosa). Bioscience Journal, 28(1):223-231.
CEAGESP - Central de Abastecimento do Estado de São Paulo (2014) Cotação diária. Disponível em: <http://www.ceagesp.gov.br/cotacoes/index html?b st art:int $=60 \&$ grupo nome $=$ Verduras \&consultar $=$ Consult ar\&grupo=3\&data=23/04/2014> (Acesso em: 19 mar. 2014).

CEASAMINAS - Central de Abastecimento de Minas Gerais (2014) Cotação diária. Disponível em: <http://www.ceasaminas.com.br> (Acesso em: 19 mar. 2014).

CONAB. Acompanhamento da Safra Brasileira de Grãos 2013/2014 - Quinto Levantamento fevereiro/2014. (2014) Disponível em: <http://www.conab.gov.br/OlalaCMS/uploads/arquivo s/14_02_11_15_22_20_boletim_graos_fevereiro_201 4.pdf $>$ (Ácesso em: 17 mar. 2014).

Cruz, C.D. Programa Genes: Biometria (2006) Viçosa: UFV 382p.

Cruz, J. C. Características agronômicas das cultivares de milho disponíveis no mercado na safra de 2013/2014. (2014) Disponível em: <http://www.cnpms.embrapa.br/milho/cultivares/CULTI VARES20132014.xls.> (Acesso em: 17 mar. 2014).

DoVale JC, Fritsche-Neto R, Lima OS (2011) Índice de seleção para cultivares de milho com dupla aptidão: minimilho e milho-verde. Bragantia, 70(4):781-787. 
EMBRAPA - CNPS (2006) Sistema Brasileiro de Classificação de Solos. Brasilia: Embrapa-SPI, 306 p.

Fancelli AL, Dourado Neto D. (2000) Produção de milho 2.ed. Guaíba: Agropecuária, 360 p.

Gao M, Qiu J, LI C, Wang L, LI H, Gao C (2014) Modeling nitrogen loading from a watershed consisting of cropland and livestock farms in China using Manure-DNDC. Agriculture, Ecosystems \& Environment, 185:88-98. doi: 10.1016/j.agee.2013.10.023

Guadagnin JP, Rodrigues LR, Emygdio BM, Ames CG, Buzzetti D, Machado JRA, Caraffa M, Trentin R (2011) Desempenho de cultivares de milho indicadas para cultivo no Rio Grande do Sul, na safra 2010/2011. Pesquisa Agropecuária Gaúcha, 17(2):183-189.

Hanashiro RK, Mingotte FLC, Fornasieri Filho D (2013) Desempenho fenológico, morfológico e agronômico de cultivares de milho em JaboticabalSP. Científica, 41(2):226-234. doi: 10.15361/19845529.2013v41n2p226-234

Lee TY, Shih YT, Huang JC, Kao SJ, Shiah FK, Liu KK (2014) Speciation and dynamics of dissolved inorganic nitrogen export in the Danshui River, Taiwan. Biogeosciences Discussions, 11(2):2.4972.536. doi: 10.5194/bg-11-5307-2014

MAPA - Ministério da Agricultura, Pecuária e Abastecimento. Ministério da Agricultura. (2012) Milho Disponível em: <http://www.agricultura.gov.br/vegetal/culturas/milho> (Acesso em: 28 mar. 2014).

Moraes ARAD, Ramos Junior EU, Gallo PB, Paterniani MEAGZ, Sawasaki E, Duarte AP, Guimarães PDS (2010) Desempenho de oito cultivares de milhoverde na safrinha, no Estado de São Paulo. Revista Brasileira de Milho e Sorgo, 9(1):79-91.

Neumann M, Sandini IE, Lustosa SBC, Ost PR, Romano MA, Falbo MK, Pansera ER (2005) Rendimentos e componentes de produção da planta de milho (Zea mays I.) para silagem, em função de níveis de adubação nitrogenada em cobertura. Revista Brasileira de Milho e Sorgo, 4(3):418-427.

Paiva MRFC, Silva GF, Oliveira FHT, Pereira RG, Queiroga FM (2012) Doses de nitrogênio e de fósforo recomendadas para a produção econômica de milho-verde na chapada do Apodi-RN. Revista Caatinga, 25(4):1-10.

Pereira Filho IA (2003) O cultivo do milho-verde. Sete Lagoas: EMBRAPA Milho e Sorgo, 217p.
Rodrigues F, Von Pinho RG, Albuquerque CJB, Faria Filho EM, Goulart JC (2009) Capacidade de combinação entre linhagens de milho visando à produção de milho-verde. Bragantia, 68(1):75-84.

Rodrigues F, Von Pinho RG, Albuquerque CJB, Von Pinho EVR (2011) Índice de seleção e estimativa de parâmetros genéticos e fenotípicos para características relacionadas com a produção de milho-verde. Ciência e Agrotecnologia, 35:278-286.

Silva FC (1999) Manual de análises químicas de solos, plantas e fertilizantes. Brasília-DF: Embrapa Comunicação para Transferência de Tecnologia, 370p.

Silva FC, Da Silva MM, Libardi PL (2013) Aplicação de nitrogênio no cultivo de milho, sob sistema plantio direto: efeitos na qualidade física do solo e características agronômicas. Semina, 34(6):3.513-3.528.

10.5433/1679-0359.2013v34n6Supl1p3513

Silva MAS, Griebeler NP, Borges LC (2007) Uso de vinhaça e impactos nas propriedades do solo e lençol freático. Revista Brasileira de Engenharia Agrícola e Ambiental, 11(1):108-114.

Soratto RP, Costa TAMD, Fernandes AM, Pereira M, Maruyama WI (2012) Parcelamento de fontes alternativas de nitrogênio no milho safrinha em sucessão à soja. Científica, 40(2):179-188. doi: 10.15361/1984-5529.2012v40n2p179+-+188

Souza RS, Vidigal Filho OS, Scapim CA, Marques OJ, Queiroz DC, Okumura RS, Reche DL, Cortinove VB (2013) Produtividade e qualidade do milho doce em diferentes populações de plantas. Semina, 34(3):995-1010 .

Yamada, T (1997) Manejo do nitrogênio na cultura do milho. In: Fancelli AL, Dourado-Neto D Tecnologia da produção de milho. Piracicaba: ESALQ, p. 121-130.

Yang G, Best EP, Whiteaker T, Teklitz A, Yeghiazarian L (2014) A screening-level modeling approach to estimate nitrogen loading and standard exceedance risk, with application to the Tippecanoe River watershed, Indiana. Journal of Environmental Management, 135(1)1-10. doi: 10.1016/j.jenvman.2014.01.003

Zucareli C, Alves GB, Oliveira MAD, Machado MH (2014) Desempenho agronômico do milho em resposta às épocas de aplicações e fontes de nitrogênio. Científica, 42(1):60-67. doi: 10.15361/1984-5529.2014v42n1p60-67 